\title{
Stylistics on the linguistics text applied in a social approach to get a certain goal
}

\author{
Georgia Elizabeth Vowel \\ School of the Art Institute of Chicago, Illinois, United States \\ David Koon Gorray \\ School of the Art Institute of Chicago, Illinois, United States \\ Nora Audrey \\ School of the Art Institute of Chicago, Illinois, United States
}

\begin{abstract}
The stylistics on the linguistics has an important role in the text applied. The social approach is one way how to get a certain goal. In this case, the brilliant solution to solve the problem based on the new method and procedure that can we did. For the public person in the word, the common way can not be avoided a social behavior as well as the community interaction. The current paper explained and explore how it can be done based on a certain way. Of course, the basic concept should be maintained, therefore, in solving the problem those are two principle concept must be had. The first is a success and the second is study.
\end{abstract}

Keywords---community, linguistics, method, social approach, stylistics.

\section{Introduction}

A key problem for stylistic text categorization, which we address here, is the proper choice of textual features for modeling style. While topic-based text categorization can get quite far by using models based on "bags of content words," style is somewhat more elusive. We start from the intuitive notion that style is indicated by features representing the author's choice of one mode of expression from a set of equivalent modes for a given content. At the surface level, this may be expressed by a wide variety of possible features of a text: choice of particular words, syntactic structures, discourse strategy, or all of the above and more. The underlying causes of such variation are similarly heterogeneous, including the genre, register, or purpose of the text as well as the educational background, social status, and personality of the author and audience. What all these dimensions of variation have in common, though, is independence from the "topic" or "content" of the text, which may be considered to be those objects and events to which it refers (as well as their properties and relations as described in the text). We may thus define the stylistic meaning of a text to be those aspects of its meaning that are nondenominational; that is, independent of the objects and events to which the text refers (Argamon et al., 2007; Kasper, 1990; Wodak, 2002).

Most computational stylistics work to date has been based on hand-selected sets of content-independent features such as function words (Matthews \& Merriam, 1997; Mosteller \& Wallace, 1964; Tweedie, Singh, \& Holmes, 1996), parts-of-speech and syntactic

Linguistics and Culture Review (C) 2017.

Corresponding author: Georgia E. Vowel, vowel.me@saic.edu

Received 18 March 2017 / Accepted 27 June 2017 / Published 09 July 2017 38 
structures (Stamatatos et al., 2000), and clause/sentence complexity measures (de Vel, 2000; Yule, 1944; also see the survey in Karlgren, 2000). While new developments in machine learning and computational linguistics have enabled larger numbers of features to be generated for stylistic analysis, in almost no case is there strong linguistic motivation behind input feature sets that would relate features directly to stylistic concerns. Rather, the general methodology that has developed is to find as large a set of topic-independent textual features as possible and use them as input to a generic learning algorithm (preferably one resistant to overfitting, and possibly including some feature selection). Some interesting and effective feature sets have been found in this way (e.g., Karlgren, 2000; Koppel, Akiva, \& Dagan, 2003); function words also have proven to be surprisingly effective on their own (Argamon et al., 2003; Argamon \& Levitan, 2005; McEnery \& Oakes, 2000). Nevertheless, we contend that without a firm basis in linguistic theory of meaning, we are unlikely to gain any true insight into the nature of the stylistic dimension(s) under study. Proper choice of features also should, of course, aid classification accuracy.

\section{Functional lexical attributes}

We first give an overview of the taxonomies underlying the functional lexical features that we have developed; more detail on the taxonomies can be found in the Appendix. This work is based on the theory of SFG, a functional approach to linguistic analysis (Halliday, 1994). SFG models the grammar of a language by a network of choices of meanings that can be expressed (Matthiessen, 1995), and so all lexical and structural choices are represented as the realizations of particular semantic and contextual meanings.

The theory, rooted in the earlier work of Firth (1968), takesa primarily sociological view of language, and has developed largely in the context of its use by applied linguists for literary/genre analysis and for studying language learning (An excellent overview of SFG and its relation to other functional accounts of grammar may be found in Butler, 2003). Describing SFG's main concerns, Matthiessen (1983) eloquently observed.

There are few grammatical mechanisms that have been developed within a framework with as impressive a tradition as Systemic Linguistics and with as wide a scope. The systemic framework is not just a non-transformational alternative to Chomsky's transformational grammar. It is different from Chomskyan work at the level of the framework, not only at the level of mechanism and notation. Systemic linguists ask questions like "How does communication succeed?", "What are the relations between context and language use?", "What can a speaker of English do grammatically to achieve a particular purpose?", "What are the options for expressing grammatically a particular range of meanings?", "What functions does language serve?" and so on. . . . One consequence of questions of this type has been in Systemic Linguistics that text as a communicative unit is taken to be the basic linguistic unit rather than the sentences that are used to express texts . . Obviously, this view has far-reaching effects on the conception of grammar (Dafouz-Milne, 2008; Sdobnikov, 2016; Hyland, 2016).

We believe that the fact that SFG models language as a network of mutually exclusive options for expressing meaning (which can be structural or lexical) makes it particularly useful for modeling stylistic variation among texts.

Systemic functional grammars have been applied to automatic natural language processing in several contexts since the 1960 s, though after the influential work of Winograd (1972) on natural language understanding, computational applications have been mostly limited to text generation (Fawcett \& Tucker, 1990; Matthiessen \& Bateman, 1991; Teich, 1995) rather than text analysis due to the complexity of parsing in the theory (but also see O’Donnell, 1993).

Briefly, SFG construes language as a set of interlocking choices for expressing meanings, with more general choices constraining the possible specific choices. A simple example in the pronominal system of English. 
If a pronoun is to be used, it may refer either to one of the discourse participants or to a third party.

- If to one of the participants, it may refer to the speaker (I, me), the speaker-plusothers (we, us), or the hearer (you);

- If to a third party, it may refer either to one individual or to many (they, them); *If to a single individual, it may refer to a conscious individual or to a nonconscious individual (it);

*If to a single conscious individual, it may refer to a male (he, him) or to a female (she, her); and so forth.

Note that a choice at one level may open up further choices at other levels, choices that are not open otherwise. For example, English does not allow a pronoun to distinguish between pluralities of conscious or nonconscious individuals. Furthermore, any specific choice of the lexical item or syntactic structure is determined by choices from multiple systems at once, as the choice between "I" and "me" is determined by the independent choice governing the pronoun's syntactic role as either a subject or an object (Bruce, 2014; Prior, 2001; Kecskes, 2000).

Thus, a system defines a set of options for meanings to be expressed. Each (nonroot) system has an entry condition, a propositional formula of options from other systems, denoting when that system is possible. Each option gives constraints (lexical, morphological, or syntactic) on utterances that express the option. Options (or logical combinations thereof) may serve as entry conditions for more specific systems. While some systems, as in the example described earlier, are disjunctive such that exactly one of their options must be chosen, others are conjunctive in that all of their options must be chosen-this enables combinatorial possibilities. For example, modal verbs (e.g., "may," "might," or "must") choose options from multiple systems, including "Modality Type" (likelihood, frequency, obligation, etc.) and "Modality Value" (median, high, low) (Kramsch, 2000; Pobegaylov et al., 2016).

\section{Discussion}

We validate our claims for the use of functional lexical features by applying them to a variety of stylistic text classification problems. In each experiment Weka's (Witten \& Frank, 2000) implementation of the SMO version (Platt, 1998) of the Support Vector Machine learning algorithm (Cristianini \& Shawe-Taylor, 2000) with a linear kernel was used for learning classification models (higher-order kernels did not seem to make much difference); for the multiclass problems, a one-versus-all strategy was used to generalize the estimate out-of-training classification accuracy, with partitions held constant for the different feature sets on each task. SMO's stiffness (C) parameter was tuned in each case by further 10-fold cross-validation over the training set (nested within evaluation cross-validation runs). Statistical significance of differences in accuracy between feature sets on the same task was estimated by the paired t-test (over the cross-validation partitions).

\section{The principal communicative-functional approach to translation}

As has been stated above, the communicative-functional approach implies consideration of a translation event in a certain, frequently imaginary, supposed, yet realistic environment within which this event happens or may happen.

The term "environment" may be replaced by the more traditional and specific concept of "communicative situation". The latter term seems to be more precise, too, as it implies the interaction of human beings. It should be borne in mind that people interact only when they need to or have to. The necessity to interact arises when any substantive work performed by people cannot be done unless they communicate. The communication can be 
both direct and indirect. In case the communication actors are divided by a language barrier, mediation by a translator/interpreter is needed. It is self-evident that a translator who performs the role of the mediator between the communication actors is supposed to take into consideration the aims with which they get engaged into the communication process, the needs and requirements of their substantive work, possible or definite ways in which they will use the target text produced (Thorne, 2008; Lemke, 1991; Short \& Leech, 2013).

Gentzler states that "...a client who hires a translator has specific goals that need consideration; the receiving audience has certain expectations that need to be addressed; translation is a form of action, a communicative interaction" (Gentzler, 2001). Only after the translator has realized the needs and expectations of the target audience, he/she is able to understand and formulate the translation goal. The notion of the translation goal is widely discussed and even widely disputed by many translation scholars.

Those who admit the relevance of the notion offer different definitions of the translation goal, according to the approach they use. The principal translation goal is not to simply produce a text that would be acknowledged as equivalent to the ST by an idle outsider who is capable of comparing the TT to the ST. It is noteworthy that in real life a translation is rarely assessed by professional critics or by those who pretend to be "critics". It is communication actors who eagerly or reluctantly assess the translation in terms of its usefulness for the activities they perform. No wonder, Christiane Nord has emphatically titled her book as "Translating as a Purposeful Activity". Thus, generally speaking, the genuine translation goal is to produce a text that would be instrumental in the activities performed by its end users (Semino \& Short, 2004; Kachru, 1990; House, 2001).

Consequently, the translation must be viewed as both the instrument of communication and the instrument of any substantive work being done by communication actors. It follows that in a professional setting, a translation event is always triggered by some aim or intention. But the question arises: whose intention is it? It seems that it is the intention of the communication actors that triggers a translation event, which is not always true. The personality of another actor is most essential in our considerations, and the actor is the initiator of translation. As Gentzler points out, it may be a person, a group, or an institution whose goals or aims may be different from those of the source-text author, the target-text receiver, and the translator (Gentzler, 2001).

The translation initiator can or cannot be directly involved in the act of communication between the actors, as the case may be. But it is always he or she (or, maybe, it, in case of some institution) who defines the character of the translation setting and, ultimately, determines the translation strategy. As I have previously pointed out, the translation strategy is a function of the initiator's goal (Sdobnikov, 2011).

Understanding by the translator of the initiator's goal and the expectations of the sourcetext author and the target text receivers' results from the analysis of the communicative situation, or the translation set, which is indispensable of any professional translation activity. The communicative situations in which translation is performed are strikingly diverse. Yet, despite this diversity, all of them fall into two main categories: 1) situations in which translation is initially planned, and 2) situations in which translation is not initially planned. In the first class of situations the text is addressed directly to the audience that speaks another language. In the second class of situations the text is addressed to the audience speaking the same language, and only after that the translation is done, in a different setting, culture and time (Mills, 2002; Simpson, 2003).

On the basis of the above premises, I can define translation as a translator's speech activity aimed at producing a text that serves to be an instrument of the substantive work 
done by the translation initiator and communication actors in the given communicative situation (Connor, 2004; De Beaugrande \& Dressler, 1981).

\section{The role of linguistic communication}

On the communicative level machine control at all stages of the organization and carrying out of construction work - from design and engineering training facility for the construction of recreation and to clean up after the completion of all construction works of the object - it is required to constantly maintain communicative contact with subordinates. At the same time, taking into account the much-documented the process of construction, regulated by different regulations, legislative acts, SNIP, etc. Control unit is required to conceptualize and optimize the existing texts, to update them to a specific time in the organization and management of production. In practice, this is achieved through a complex process of inclusion of the text of the existing regulatory framework in the texts of the adaptive nature of optimization and regulating the progress of work in view of the chosen management model.

The larger the organization, the more complex and heterogeneous process of exchanging text information control and reporting nature. Analysis of a typical workflow of a large construction company suggests three qualitative and quantitative level, which forms the text information: 1) Top managers of the company, senior managers. The device managers create the overall strategy of the company, decides to conceptual issues of development and implementation of production. It makes key decisions. In terms of communication, the level of top management is initiating, a feedback position, the end. 2) The mid-level management device implements supplied fuel Task Managers issued usually in the form of a written order, ie, text. On the communicative level, this refers to the expansion of the information channel, the processing, and transformation of raw data into a considerable amount of texts containing additional relevant information. At this stage already formed an inverse relationship between top managers and middle-level administrative apparatus, which has a separate information field, channel, given the amount of information and interaction model. 3) Ispolnitelnoe field unit receives the information and implements it during the preparation of the final product. At the same actuator on the ground and adapts to the received texts specifics of the situation. The actuator is the final recipient of the information in the communication circuit for a direct connection and initial feedback global communication within the company. Preparation of written progress reports, requests for additional information, and so on. N. Is the bulk of the texts produced at this level.

\section{From texts to social contexts}

Since 1966, when Kaplan's original work on contrastive rhetoric appeared, and 1996, when my book on contrastive rhetoric was published, many new trends have appeared in research approaches and methods. The change has been affected by two major developments, namely an expansion of genres under consideration and a move to emphasize contexts of writing. First, there has been an increase in the types of written texts that are considered the purview of second language writing around the world. EAP classes teach other types of writing besides the student essay required in college classes. Other important genres are the academic research article, research report, and grant proposal. Writing for professional purposes, such as business, is also now considered a legitimate type of second language writing and worthy of research and teaching.

In addition to the expansion of the genre, the field has moved to emphasize the social situation of writing. Today, writing is increasingly regarded as being socially situated; each situation may entail special consideration to audience, purposes, level of perfection, and correspondingly may require varying amounts of revision, collaboration, and attention to detail. The expectations and norms of discourse communities or communities of practice 
(cultural and disciplinary), of course, may shape these situational expectations and practices. The social construction of meaning as dynamic, socio-cognitive activities is a term used to describe this approach to texts. Instead of analyzing what texts mean, we want to understand how they construct meaning. Bazerman \& Prior (2004) pose three questions to guide the analysis of writing: "What does the text talk about? How do texts influence audiences? And how do texts come into being?" Thus, two major reasons-the acknowledgment of more genres with specific textual requirements and the social contexts of writing-have motivated scholars of intercultural rhetoric to adjust and supplement research approaches in their work.

These changes in teaching and research of writing are reflected by Flowerdew in a recent book, Academic Discourse (2002). Flowerdew divides research on written academic English into four different methodological categories: genre analysis, corpus-based studies, contrastive rhetoric, and ethnographic/naturalistic approaches.

According to Flowerdew, genre analysis is textual analysis and provides narrow (specific to certain genres, not to all academic discourse) and deep descriptions of academic discourse by focusing on specific genres such as the academic research paper (Swales, 1990) or the work on business, academic, and legal discourses of Bhatia (1993). Genre analysis produces generic structures of moves that provide the basis for the development of pedagogic materials as in Swales \& Feak (1994, 2001). Corpus linguistics allows for the consistent and accurate analyses of large databases.

Contrastive rhetorical analysis of academic discourse, according to Flowerdew (2002), shows that there are preferred expectations about how information is organized in different languages and cultures and that these preferential expectations can be used in the development of pedagogic materials. The ethnographic approach views text as only one feature of the social situation in which writing takes place. In addition to textual analysis, ethnographic methods emphasize direct observation, interviews, and other modes of analyzing the situational context. Unlike applications of the other three methodologies, Flowerdew (2002) maintains that ethnographic academic discourse analysis, being contextually restricted, maybe "less amenable to large-scale application to pedagogic materials."

\section{Current series on intercultural studies}

A new series on intercultural studies, Cultures, and Communication, has recently been launched by Jörg Roche and Willie van Peer, both at the University of Munich. The series is being published by LIT in Münster and aims to be bilingual (German and English manuscripts are awaited). More information can be found on the website, at http://www.lit-verlag.de/reihe/kukcac.

In our increasingly globalized world, communication between cultures is attracting more and more attention. It is becoming increasingly clear that successful intercultural or transcultural communication is developed through mediation processes, rather than by simple 'transmission of knowledge' alone. Unfortunately, this understanding is often arrived at too late, only after conflicts or miscommunication have occurred. By that time, the opportunity for analyzing the communication process has often been lost, in part because communicators may be unwilling to collaborate with 'outside' professionals on such an analysis.

It is also true that while some sophisticated communication concepts have proven themselves to be indispensable for intercultural training, therapeutic interventions or the teaching of language and culture within an intercultural framework, such concepts and models are only credible when firmly grounded on theory-based research. This series is therefore motivated by the goal of contributing to well-founded, differentiated and 
interdisciplinary research on psychological, cultural-anthropological, media-related, hermeneutical, literary, medical, pedagogical, educational and policy-related aspects of communication between cultures.

This approach is oriented squarely towards the translation text: A translation is evaluated predominantly in terms of its forms and functions inside the system of the receiving culture and literature (cf. Toury 1995). The original is of subordinate importance, the main focus-retrospective from translation to original-being "actual translations," and the textual phenomena that have come to be known in the target culture as translations.

The idea is to first of all attempt to "neutrally" describe the characteristics of that text as they are perceived on the basis of native (receptor) culture members' knowledge of comparable texts in the same genre. However, if one aims at judging a particular text which is plainly not an "independent," "new" product of one culture only, such a retrospective focus seems peculiarly inappropriate for making valid statements about how and why a translation qua translation is as it is. While the solid empirical-descriptive work and the emphasis put on contextualization at the microlevel of the reception situation and the macro-level of the receiving culture at large, as well as the inclusion of both a "longitudinal" (temporal, diachronic) and a (synchronic) systemic perspective (considering the polysystemic relations into which the translation enters with other texts in the receiving cultural system), is certainly commendable, the approach does fail to provide criteria for judging the merits and weaknesses of a particular "case." In other words, how are we to judge whether one text is a translation and another one not? And what are the criteria for judging merits and weaknesses of a given "translation text"?

Scholars belonging to this approach (cf. e.g. Venuti 1995) try to critically examine translation practices from a psycho-philosophical and socio-political stance in an attempt to unmask unequal power relations, which may appear as a certain skewing in the translation. In a plea for making translations (and especially translators as their "creators") "visible" and for revealing ideological and institutional manipulations, proponents of this approach aim to make politically pertinent (and "correct") statements about the relationship between features of the original text and the translation text. They focus on the hidden forces shaping both the process of selecting what gets translated in the first place and the procedures that result in the ways original texts are bent and twisted in the interests of powerful individuals and groups "pulling strings" when choosing texts for translation and adopting particular strategies of re-textualization.

This is certainly a worthwhile undertaking, especially when it comes to explaining the influence translators can exert through their translation on the receiving national literature and its canon. Further, the application of currently influential lines of thinking such as post-colonial theory (Robinson 1997) or feminist theory (von Flotow 1997) to translate may not be uninteresting in itself. However, if comparative analyses of original and translation focus primarily on the shifts and skewings stemming from ideologically motivated manipulations, and if an agenda is given priority which stresses the theoretical, critical and textual means by which translations can be studied as loci of difference," one wonders how one can ever differentiate between a translation and any other text that may result from a textual operation which can no longer claim to be in a translation relationship with an original text.

Fludernik's (1993) study of what she calls free indirect discourse is even more impressive in terms of the wide range of textual examples she uses to illustrate the points she wants to make. We have learned much from her work but, as with Cohn's study, we were concerned that her relatively informal analytical approach might mean that important factors in the study of discourse presentation would be missed. In her research, Fludernik specifically considered the possibility of a corpus-based approach, and the quantification that comes with it, but rejected this option (i) because she did not want to restrict herself 
to the literature of just one language, nation, period, etc., which she thought a corpusbased approach would prevent, and (ii) because she believed that a corpus and its associated annotation would have created serious methodological problems, in the sense that she thinks it would have been necessary to institute arbitrary definitions of the relevant categories' (Fludernik, 1993).

Such arbitrariness would necessarily have resulted in an erosion of the actual usefulness of the statistical data since one would have had either to decide on larger categories that include marginal and ambiguous phenomena or to indulge in a proliferation of subcategories and intermediary categories which would have rendered the statistics next to useless for interpretation. From previous experience with statistical research (Fludernik, 1982). We have also acquired a profound distrust of the methodological relevance of statistical data. Statistics typically take individual occurrences of certain phenomena out of context. Since the present study attempts to document the crucial importance of context for the purpose of the even preliminary establishment of basic categories, a statistical approach would from the outset have vitiated one of the major aims of the project. These remarks are, however, not meant to discredit statistical research in itself. On the contrary, I would welcome a series of statistical analyses that might help to corroborate, modify or refute some of the theses I am here proposing (Fludernik 1993).

We have quoted from Fludernik at length because we have effectively tried to do what she decided to avoid, namely to use a set of categories and subcategories to analyze the textual extracts in our corpus comprehensively and systematically. Consequently, we certainly recognize some of the problems she points to, though we think that the annotation difficulties have not been as damaging as she thought they would be. Indeed, we would claim that forcing ourselves to be as clear and precise as possible about our annotations has helped us to isolate and come to terms with, phenomena we may not otherwise even have noticed. Similarly, we believe that forcing ourselves to account for ambiguity and marginal phenomena in our annotations has helped us to understand more exactly how the speech, writing and thought presentation scales operate, and what factors are at work in producing ambiguity on those scales. Because we take this explicit analytical approach, we are able to provide some of the statistical information which, at the end of the above quotation, Fludernik says that she would welcome.

We very much agree with Fludernik that statistical analysis has limitations as well as advantages, and this is why we present both quantitative and qualitative analysis in this book. We do not think that the one precludes the other (though doing both does increase the workload still further, as, from experience, we are very well aware). Indeed, we would want to argue that both forms of analysis are needed, and work best when used interdependently. Although Fludernik decided not to adopt a corpus-based and quantitative approach (the experience of the dissertation she refers to as Fludernik (1982) was clearly salutary!), she makes a point of saying that she is not antipathetic to such work. She is very open to the fact that all approaches have advantages and disadvantages, and that we can all learn from different approaches to the same phenomenon. This tolerant and inclusive attitude is in contrast to the attacks on corpus linguistics by some other linguists, which we allude to briefly below.

It was natural for us to move to a corpus-based approach as we work in a department which has members who have been involved in corpus construction and annotation for some years, and who could easily be called upon for advice and help. The LancasterOslo/Bergen (LOB) corpus was one of the early modern linguistic corpora to be developed; Lancaster is the 'home' of the British National Corpus (BNC), for which Lancaster did much of the work, and our colleagues are involved in the building and exploitation of other corpora too. However, not all linguists are sympathetic to a corpus-based approach, and so we will take a little space here to explore some of the pros and cons in the use of electronic 
corpora, to help explain our decision to develop our corpus and to use 'corpus stylistics' as the main title of this book.

The first point that we would like to make is that although this book, and much of our current work, involves the use of a corpus-based approach in stylistics, we do not think that this approach should supplant other work within our field. Rather, our decision to use a corpus-based approach was because it was the best tool we could find to carry out the particular kind of investigation we had in mind. In order to see how adequate the Leech and Short model was, and what kind of modifications it might require, we needed to test the model on a number of different text types, with enough samples of each text-type to be reasonably sure of our findings.

This led to the idea of a representative corpus. We also needed to force ourselves not just to concentrate on convenient text- or intuition-based examples. This led to the idea of developing a method of systematic and replicable textual annotation which would be used comprehensively. Finally, we needed to be able to sort our annotations easily, in order to observe patterns of various kinds in our data. This need led naturally to the idea of using an electronically tagged corpus, and software that would enable us to do what we wanted (we chose Mike Scott's Wordsmith package for this purpose).

The fact that we are currently involved in corpus-based work, and the quantification that it entails, does not mean that we have stopped doing the qualitative textual analysis that is at the heart of the field of stylistic analysis. We are still involved in this sort of work, and will continue to do it (indeed this book includes some qualitative work on particular texts in our corpus; see Chapter 8 in particular). We will continue to use our intuition in arriving at theories, interpretations of texts and so on, and we will not give up our interest in investigating informant reactions to texts in order to compare them with stylistic analyses or stylistic theories - or indeed any other kind of work we, or other statisticians, typically engage in.

\section{Conclusion}

We think that all these different approaches have a useful role to play in helping us (i) to understand how readers interact with and understand, particular texts and (ii) to arrive at general theories of textual understanding, textual response, and style. We would be unhappy if the work we report was regarded as a competitor for other forms of inquiry in stylistics, rather than as merely another (very useful) approach to add to the analytical armory of the stylistics enterprise. There is already some interesting work that insightfully combines detailed qualitative work on particular texts with corpus-based analysis. It uses such a combination to show how Baden-Powell, the founder of the Boy Scout movement, use the same lexical items in very different (and sexist) ways in his last messages to corpus-based work to show, for example, how what he calls the 'semantic prosody' of the word 'utterly' is used by Philip Larkin to induce feelings of threat at the end of 'First Sight'

\section{References}

Edelsky, C., Smith, K., \& Wolfe, P. (2002). A discourse on academic discourse. Linguistics and Education, 13(1), 1-38. https://doi.org/10.1016/S0898-5898(01)00065-1

Argamon, S., Koppel, M., Fine, J., \& Shimoni, A. R. (2003). Gender, genre, and writing style in formal written texts. Text-The Hague Then Amsterdam Then Berlin-, 23(3), 321346. https://doi.org/10.1515/text.2003.014

Prior, P. A., \& Bazerman, C. (2004). What writing does and how it does it: An introduction to analyzing texts and textual practices.

Bhatia, K., \& Huppi, K. (1993). U.S. Patent No. 5,272,057. Washington, DC: U.S. Patent and Trademark Office. 
Butler, E. A., Egloff, B., Wlhelm, F. H., Smith, N. C., Erickson, E. A., \& Gross, J. J. (2003). The social consequences of expressive suppression. Emotion, 3(1), 48.

Cristianini, N., \& Shawe-Taylor, J. (2000). An introduction to support vector machines and other kernel-based learning methods. Cambridge university press.

Shawe-Taylor, J., \& Cristianini, N. (2000). Support vector machines. An Introduction to Support Vector Machines and Other Kernel-based Learning Methods, 93-112.

Firth, J. R., \& Strevens, P. D. (1968). The tongues of men and speech.

Firth, J. R. (1968). Descriptive linguistics and the study of English. na.

Flowerdew, J. (2002). Genre in the classroom: A linguistic approach. Genre in the classroom: Multiple perspectives, 91-102.

Flowerdew, J. (2002). Ethnographically inspired approaches to the study of academic discourse. Academic discourse, 235-252.

Fludernik, M. (2003). The fictions of language and the languages of fiction. Routledge.

Fludernik, M. (1991). Shifters and deixis: Some reflections on Jakobson, Jespersen, and reference. Semiotica, 86(3-4), 193-230.

Fludernik, M. (1993). Second person fiction: Narrative" you" as addressee and/or protagonist. AAA: Arbeiten aus Anglistik und Amerikanistik, 217-247.

Fludernik, M. (1993). Narratology in Context.

Fludernik, M. (2003). Chronology, time, tense and experientiality in narrative. Language and Literature, 12(2), 117-134.

Gentzler, E. (2001). Contemporary translation theories (Vol. 21). Multilingual Matters.

Gentzler, E. (2012). Translation and identity in the Americas: New directions in translation theory. Routledge.

Halliday, F. (1994). Rethinking international relations. Macmillan International Higher Education.

Halliday, F. (1994). Hidden from international relations: women and the international arena. In Rethinking International Relations (pp. 147-169). Palgrave, London. https://doi.org/10.1007/978-1-349-23658-9_7

Karlgren, J. (2000). Information retrieval: Statistics and linguistics. Excerpt from the PhD Thesis" Stylistic Experiments in Information Retrieval.

Koppel, M., Akiva, N., \& Dagan, I. (2003). A corpus-independent feature set for style-based text categorization. In Proceedings of IJCAI'O3 Workshop on Computational Approaches to Style Analysis and Synthesis, Acapulco, Mexico (pp. 61-67).

Matthews, C. E., Hebert, J. R., Ockene, I. S., Saperia, G., \& Merriam, P. A. (1997). Relationship between leisure-time physical activity and selected dietary variables in the Worcester Area Trial for Counseling in Hyperlipidemia. Medicine and science in sports and exercise, 29(9), 1199-1207. https://doi.org/10.1097/00005768-199709000-00013

Matthiessen, C., \& Bateman, J. A. (1991). Text generation and systemic-functional linguistics: experiences from English and Japanese. Pinter Publishers.

Matthiessen, C. M. I. M., \& Bateman, J. A. (1991). Systemic linguistics and text generation: experiences from Japanese and English. London: Pinter.

Matthiessen, C. M. I. M., \& Bateman, J. (1991). Text generation and systemic linguistics: experiences from English and Japanese. London: Pinter.

Matthiessen, C. M. (1983). Nigel: A Systemic Grammar for Text Generation (No. ISI/RR-83105). University of southern california marina del rey information sciences inst.

Matthiessen, A. (1998). Reduction of divalent mercury by humic substances-kinetic and quantitative aspects. Science of the total environment, 213(1-3), 177-183. https://doi.org/10.1016/S0048-9697(98)00090-4

McEnery, A. M., \& Oakes, M. P. (2000). Authorship studies/textual statistics.

Oakes, M., \& McEnery, T. (2000). Chapter One: Bilingual text alignment-an overview. Language And Computers, 22, 1-37.

Mosteller, F., \& Wallace, D. (1964). Inference and disputed authorship: The Federalist.(1964).

O'Donnell, G. (1993). On the state, democratization and some conceptual problems: A Latin American view with glances at some postcommunist countries. World Development, 21(8), 1355-1369. https://doi.org/10.1016/0305-750X(93)90048-E 
Platt, J. (1998). Sequential minimal optimization: A fast algorithm for training support vector machines.

Robinson, R. G. (1997). Determination of radial coefficient of consolidation by the inflection point method. Geotechnique, 47(5), https://doi.org/10.1680/geot.1997.47.5.1079

Sdobnikov, V. V. (2011). Translation strategy: General definition. Vestnik of Irkutsk State Linguistic University, (1), 165-172.

Swales, J. M., \& Feak, C. B. (1994). Academic writing for graduate students. Ann Arbor: University of Michigan Press.

Swales, J. M., \& Feak, C. B. (2004). Academic writing for graduate students: Essential tasks and skills (Vol. 1). Ann Arbor, MI: University of Michigan Press.

Swales, J. M. (1990). Discourse analysis in professional contexts. Annual review of applied linguistics, 11, 103-114. https://doi.org/10.1017/S0267190500001987

Teich, M., Young, R. M., \& Needham, J. (1973). Changing Perspectives in the History of Science Essays in Honour of Joseph Needham.

Toury, G. (1995). The Notion of 'Assumed Translation'-An Invitation to a New Discussion. Letterlijkheid, Woordelijkheid/Literality, Verbality, 135-147.

Tweedie, F. J., Singh, S., \& Holmes, D. I. (1996). Neural network applications in stylometry: The Federalist Papers. Computers and the Humanities, 30(1), 1-10. https://doi.org/10.1007/BF00054024

Venuti, L. (1995). The Translator's Invisibility. London and New York. Routledge. New York Times "California Seeks to Stop the Use of Child Medical Interpreters, Published: October, 30, 2005.

Von Flotow, L. (2010). Gender in translation. Handbook of Translation Studies, 1, 129-133.

Winograd, T. (1972). Understanding natural language. Cognitive psychology, 3(1), 1-191. https://doi.org/10.1016/0010-0285(72)90002-3

Witten, I. H., \& Frank, E. (2000). Weka. Machine Learning Algorithms in Java, 265-320.

Connor, U. (2004). Intercultural rhetoric research: Beyond texts. Journal of English for Academic Purposes, 3(4), 291-304. https://doi.org/10.1016/j.jeap.2004.07.003

De Beaugrande, R., \& Dressler, W. U. (1981). Introduction to text linguistics. Routledge.

Mills, S. (2002). Feminist stylistics. Routledge.

Simpson, P. (2003). Language, ideology and point of view. Routledge.

Semino, E., \& Short, M. (2004). Corpus stylistics: Speech, writing and thought presentation in a corpus of English writing. Routledge.

Kachru, B. B. (1990). World Englishes and applied linguistics. World Englishes, 9(1), 3-20. https://doi.org/10.1111/j.1467-971X.1990.tb00683.x

House, J. (2001). Translation quality assessment: Linguistic description versus social evaluation. Meta: journal des traducteurs/Meta: translators' Journal, 46(2), 243-257.

Thorne, S. L. (2008). " Bridging activities," new media literacies, and advanced foreign language proficiency. Calico Journal, 25(3), 558.

Lemke, J. L. (1991). Text production and dynamic text semantics. Functional and systemic linguistics: Approaches and uses, 23.

Short, M. H., \& Leech, G. N. (2013). Style in fiction: A linguistic introduction to English fictional prose. Routledge.

Argamon, S., Whitelaw, C., Chase, P., Hota, S. R., Garg, N., \& Levitan, S. (2007). Stylistic text classification using functional lexical features. Journal of the American Society for Information Science and Technology, 58(6), 802-822. https://doi.org/10.1002/asi.20553

Kasper, G. (1990). Linguistic politeness:: Current research issues. Journal of pragmatics, 14(2), 193-218. https://doi.org/10.1016/0378-2166(90)90080-W

Wodak, R. (2002). Aspects of critical discourse analysis. Zeitschrift für Angewandte Linguistik, 36(10), 5-31.

Kramsch, C. (2000). Second language acquisition, applied linguistics, and the teaching of foreign languages. The Modern Language Journal, 84(3), 311-326. https://doi.org/10.1111/0026-7902.00071 
Pobegaylov, O. A., Myasishchev, G. I., \& Gaybarian, O. E. (2016). Organization and Management Efficiency Assessment in the Aspect of Linguistic Communication and Professional Text. Procedia Engineering, 150, 2173-2177. https://doi.org/10.1016/j.proeng.2016.07.260

Bruce, I. (2014). Expressing criticality in the literature review in research article introductions in applied linguistics and psychology. English for Specific Purposes, 36, 85-96. https://doi.org/10.1016/j.esp.2014.06.004

Prior, P. (2001). Voices in text, mind, and society: Sociohistoric accounts of discourse acquisition and use. Journal of second language writing, 10(1-2), 55-81. https://doi.org/10.1016/S1060-3743(00)00037-0

Kecskes, I. (2000). A cognitive-pragmatic approach to situation-bound utterances. Journal of pragmatics, 32(5), 605-625. https://doi.org/10.1016/S0378-2166(99)00063-6

Dafouz-Milne, E. (2008). The pragmatic role of textual and interpersonal metadiscourse markers in the construction and attainment of persuasion: A cross-linguistic study of newspaper discourse. Journal of pragmatics, 4O(1), 95-113. https://doi.org/10.1016/j.pragma.2007.10.003

Sdobnikov, V. (2016). In defense of communicative-functional approach to translation. Procedia-Social and Behavioral Sciences, 231, 92-98. https://doi.org/10.1016/j.sbspro.2016.09.076

Hyland, K. (2016). Methods and methodologies in second language writing research. System, 59, 116-125. https://doi.org/10.1016/j.system.2016.05.002

Galbraith, D., \& Rijlaarsdam, G. (1999). Effective strategies for the teaching and learning of writing. Learning and instruction, 9(2), 93-108. https://doi.org/10.1016/S09594752(98)00039-5

Yule, J. A. C. (1944). Unsharp marks. Photographic Journal, 84, 321-327.

Fawcett, R. P., \& Tucker, G. H. (1990, August). Demonstration of GENESYS: A very large, semantically based systemic functional generator. In Proceedings of the 13th conference on Computational linguistics-Volume 1 (pp. 47-49). Association for Computational Linguistics.

Bateman, J., Matthiessen, C., Nanri, K., \& Zeng, L. (1991, August). The re-use of linguistic resources across languages in multilingual generation components. In Proceedings of the 12th international joint conference on Artificial intelligence-Volume 2 (pp. 966-971). Morgan Kaufmann Publishers Inc..

Bateman, J. A., Matthiessen, C., Nanri, K., \& Zeng, L. (1991, August). The rapid prototyping of natural language generation components: an application of functional typology. In Proceedings of the 12th international conference on artificial intelligence (pp. 966-971).

De Vel, O. (2000, August). Mining e-mail authorship. In Proc. Workshop on Text Mining, ACM International Conference on Knowledge Discovery and Data Mining (KDD'2000).

Argamon, S., Šarić, M., \& Stein, S. S. (2003, August). Style mining of electronic messages for multiple authorship discrimination: first results. In Proceedings of the ninth $A C M$ SIGKDD international conference on Knowledge discovery and data mining (pp. 475-480). ACM. https://doi.org/10.1145/956750.956805

Argamon, S., \& Levitan, S. (2005, June). Measuring the usefulness of function words for authorship attribution. In Proceedings of the 2005 ACH/ALLC Conference (pp. 4-7). 